Research Paper / Araştırma Makalesi

\title{
E7 Ülkelerinde Kilit Sektör Analizi
}

\author{
Abdullah TOPCUOĞLU ${ }^{1}$ ve Fatih Volkan AYYILDIZ ${ }^{2}$ \\ $\ddot{O} z$
}

Gelişmekte olan ülkelerin sosyo-ekonomik açıdan ilerleyebilmesi ve gelişmiş ülkeler seviyesine çıkabilmeleri için üretim seviyelerini arttırarak ekonomik büyümeyi sağlamaları gerekmektedir. Ekonomik büyümenin sağlanması sürecinde de ekonomik karar vericilerin yatırımları doğru alanlara kanalize etmesi gerekmektedir. Çin, Hindistan, Brezilya, Meksika, Endonezya, Rusya ve Türkiye, gelişme hızının yüksek olduğu ülkeler olarak E7 (emerging) ülkeleri olarak adlandırılmaktadır. Ekonomistler, E7 ülkelerinin sahip oldukları kaynakları doğru alanlara yönlendirmeleri durumunda yüksek bir gelişme hızı yakalayacaklarını ve ilerleyen yıllarda da dünya ekonomisinde üst sıralara yükseleceklerini ileri sürmektedirler. Bu süreçte, E7 ülkelerinin doğru alanlara yatırım yapabilmesi için ekonomideki "kilit sektörleri" doğru tespit edebilmesi ve bu sektörlere yatırım yapması büyük önem arz etmektedir. Kilit sektörler sahip oldukları yüksek ileri ve geri yönlü bağlantı etkileriyle ekonomideki diğer endüstrilerin ve sektörlerin de gelişme hızını olumlu yönde etkileyen sektörlerdir. Bu çalışmada E7 ülkelerinin toplam ileri ve geri yönlü bağlantı etkileriyle bu ülkelerin kilit sektörleri 2014 yılı WIOD verileri aracılığı ve Girdi-Çıktı analizi ile tespit edilmeye çalışılmıştır.

Anabtar Kelimeler: E7 Ülkeleri, Kilit Sektör Analizi, Girdi-Çıktı Analizi

\section{Key Sector Analysis in E7 Countries}

\section{Abstract}

Developing countries need to achieve economic growth by increasing their production levels so that they can progress in socio-economic terms and to reach the level of developed countries. In the process of achieving economic growth, economic decision makers need to channel investments into the right areas. China, India, Brazil, Mexico, Indonesia, Russia and Turkey as countries with a high growth rate are called the E7 countries. Economists argue that if the E7 countries direct their resources to the right areas, they will achieve a high rate of growth and in the following years they will rise to the top of the world economy. In this process, it is very important for E7 countries to identify correctly the key sectors in the economy and invest in these sectors so that they can invest in the right areas. The key sectors are the sectors with high forward and backward linkages that positively affect the growth rate of other sectors in the economy. In this study, total forward and backward linking effects of E7 countries and the key sectors of these countries are tried to be determined by using Input-Output analysis by using WIOD data of 2014.

Key Words: E7 Countries, Key sector analysis, Input-output analysis

Atıf İçin / Please Cite As:

Topcuoğlu, A. ve Ayyıldız, F. V. (2020). E7 ülkelerinde kilit sektör analizi. Manas Sosyal Arastırmalar Dergisi, 9(2), 822-833.

Geliş Tarihi / Received Date: 06.06.2019

Kabul Tarihi / Accepted Date: 23.10.2019

\footnotetext{
${ }^{1}$ Dr. Öğr. Üyesi - Ardahan Üniversitesi, İktisadi ve İdari Bilimler Fakültesi, abdullahtopcuoglu@ardahan.edu.tr ORCID: 0000-0002-7857-6021

2 Öğr. Gör. - Ardahan Üniversitesi, İktisadi ve İdari Bilimler Fakültesi, fatihvolkanayyildiz@ardahan.edu.tr ORCID: 0000-0001-5991-3574
} 


\section{Giriş}

İktisadi büyüme ve kalkınma süreçleri, gelişmiş ve gelişmekte olan ülkeler bakımından önemli ekonomi politikalarının başında gelmektedir. Ülkeler iktisat politikalarını belirlerken, esasen bu politikalarla ilgili hedeflerin gerçekleştirilebilmesi ve istenen sonuçların alınabilmesi için endüstriler arası mal-hizmet akımlarının nasıl gerçekleştiğini ve ekonomideki etkin sektörleri bilmelidir. Uzun dönem perspektifinde, büyüme maksimizasyonunun sağlanabilmesi için ekonominin önemli kilit sektörlerine daha fazla kaynak tahsis edilmesi gerektiği söylenebilir. Başka bir deyişle, sektörler arası ilişkiler ekonomik yapıyı anlamak ve dolayısıyla ekonomik politikaları uyarlamak için gerçekten önemli ve gereklidir. Bu çerçevede ister gelişmiş isterse de gelişmekte olan ülke olsun tüm ülkelerin endüstriler arası analizlere ve dolayısıyla Girdi-Çıktı modellerine ihtiyaçları olduğu söylenebilir. Girdi - Çıktı analizi, tüm ülkeler tarafindan genel kabul gören ve kullanılan önemli bir analiz aracıdır. Girdi - Çıktı analizi aracıllğılyla bir ülkenin hangi endüstriye ne kadar kaynak ayıracağı, hangi sektörlerin kilit öneme sahip olduğu ve çarpan etkisinin yüksek olduğu sektörler belirlenebilir.

Kilit sektörler, gelişmeyi farklı kanallara yayarak ve ekonomideki tüm sektörleri etkilemektedir. Farklı ülkelerde, uzun vadede ekonomik büyümeyi teşvik etmek için sermaye malları sektörlerinde önemli miktarda kaynak tahsis edilmesi gerekliliği bilinen bir gerçektir. Kaynakların yetersizliği nedeniyle, özellikle gelişmekte olan ülkelerde, tüm ekonomik sektörlerin aynı anda gelişmesinin mümkün olmadığ1 düşünüldügünde, kilit sektörlerin belirlenmesi önemli bir ihtiyaçtır (Jahangard ve Keshtvarz, 2012, s.45).

Bu çalışmanın amacı, E7 ülkelerinin Girdi-Çıktı tabloları aracıllı̆̆yla, bu ülkelerin endüstrilerine ait toplam ileri ve geri yönlü bağlantı etkilerini ve E7 ülkelerindeki kilit sektörlerin belirlenmesidir. Ayrıca yapılan analizler sonucunda E7 ülkelerindeki üretim yapısına ve yatırımlara yönelik öneriler sunulması da amaçlanmaktadır. Çalışma, yüksek gelişme hızına sahip ülkeler olarak adlandırılan E7 ülkelerinin kilit sektörlerinin belirlenmesi ve planlama sürecinde yatırımların doğru sektörlere yöneltilmesi bakımından önem arz etmektedir. Kilit sektörlerin belirlenmesinin, ekonomik karar vericilerin uygulayacakları kalkınma politikaları ve bu politikaların daha etkin sonuçlar vermesi hususunda önemli bir kaynak oluşturacağı söylenebilir. Analiz verileri World Input-Output Database'den (Timmer vd., 2015, s.575) alınan, 2014 yll Çin, Hindistan, Brezilya, Meksika, Endonezya, Rusya ve Türkiye'ye ait Girdi-Çıktı tablolarıdır. Çalışmada önce E7 Ülkelerinin genel ekonomik yapısı açıklandıktan sonra kilit sektörlerin analizinde Girdi-Çıktı modelinin kullanıldığı literatür taraması verilmiştir. Devamında çalışmanın yönetimi olan Girdi-Çıktı analizi ile ilgili teorik bilgi verilmiş ve WIOD'dan alınan verilerin analiz sürecine hazırlanması ve yapılan analizler sonucunda elde edilen toplam ileri ve toplam geri yönlü bağlantılar ve kilit sektörler ile ilgili bilgiler verilmiştir. Elde edilen analiz sonuçlarına göre, çalş̧manın sonuç ve değerlendirme kısmında gerekli yorumlar yapılarak, bazı politika önerileri sunulmuştur.

\section{E7 Ülkelerinde Ekonomik Yap1}

Gelişme hızının yüksek olduğu E7 ülkeleri Çin, Hindistan, Brezilya, Meksika, Rusya, Endonezya ve Türkiye'den oluşmaktadır. Tablo 1'e göre, E7 ülkeleri içerisinde 2010-2017 y1lları arasında en yüksek büyüme oranı Türkiye'de 2011 yllında (\%11,1) gerçekleşmiştir. 2010-2017 dönemi dikkate alındığında Türkiye hariç diğer ülkelerinin tamamı en yüksek büyüme oranlarına 2010 da ulaşmıştır. 2011 yll hariç, 2010-2013 yılları arasında E7 ülkeleri içerisinde en yüksek büyüme hızı Çin'e ait iken, 2014-2017 y1llarında ise E7 ülkelerinde en yüksek büyüme hızına Hindistan ulaşmışır. Hindistan'ın büyüme hızının 2014 de Çin'i geçmiş olmasının nedeni katma değeri yüksek olan BT (Bilişim Teknolojileri) ve yazılım konusunda ana ihracatçı ülke haline gelmiş olmasıdır. 2010-2017 y1lları arasında E7 ülkelerinden sadece Rusya ve Brezilya 2015-2016 yıllarında iktisadi daralma yaşamışır. 2010-2017 yılları dikkate alındığında E7 ülkeleri ortalama büyüme hızın 2010 'da \%9,14 ile en yüksek, 2016'da ise \%3,02 ile en düşük olduğu görülmektedir. 
Tablo 1. E7 Ülkelerinin 2010-2017 Döneminde Büyüme Oranları (\%)

\begin{tabular}{lcccccccc}
\hline Ülkeler & $\mathbf{2 0 1 0}$ & $\mathbf{2 0 1 1}$ & $\mathbf{2 0 1 2}$ & $\mathbf{2 0 1 3}$ & $\mathbf{2 0 1 4}$ & $\mathbf{2 0 1 5}$ & $\mathbf{2 0 1 6}$ & $\mathbf{2 0 1 7}$ \\
\hline Çin & 10,6 & 9,5 & 7,9 & 7,6 & 7,3 & 6,9 & 6,7 & 6,9 \\
Hindistan & 10,3 & 6,6 & 5,5 & 6,4 & 7,4 & 8 & 8,2 & 7,2 \\
Brezilya & 7,5 & 4 & 1,9 & 3 & 0,5 & $-3,5$ & $-3,3$ & 1 \\
Meksika & 5,1 & 3,7 & 3,6 & 1,4 & 2,8 & 3,3 & 2,9 & 2 \\
Endonezya & $\mathbf{6 , 2}$ & $\mathbf{6 , 1}$ & 6 & 5,6 & 5 & 4,9 & 5 & 5,1 \\
Rusya & 4,5 & 5,3 & 3,7 & 1,8 & 0,7 & $-2,8$ & $-0,2$ & 1,6 \\
Türkiye & 9,2 & 11,1 & 4,8 & 8,5 & 5,2 & 6,1 & 3,2 & 7,4 \\
\hline E7 Ortalama Büyüme Hiz1 & $\mathbf{9 , 1 4}$ & $\mathbf{6 , 6 1}$ & $\mathbf{4 , 7 7}$ & $\mathbf{4 , 9 2}$ & $\mathbf{4 , 1 2}$ & $\mathbf{3 , 2 7}$ & $\mathbf{3 , 0 2}$ & $\mathbf{4 , 4 5}$ \\
\hline
\end{tabular}

Kaynak: Dünya Bankası, GSYİH Büyüme Oranı (Yıllık, \%)

Tablo 2'ye bakıldığında E7 ülke grubu 2010-2017 yılları arasındaki bilgiler incelendiğinde; Rusya'nın 2015 ve 2016 yllları hariç kişi başına GSYİH (Gayrisafi Yurtiçi Hasıla) 10.500\$ üzerinde olduğu, Türkiye'nin ise kişi başına GSYIH'nın 10.500\$ üzerinde olduğu, Brezilya'nın 2015,2016 ve 2017 yılları hariç kişi başına GSYIH'nı 11.000\$ üzerinde olduğu görülmektedir. 2010-2017 yılları arasında E7 ülke grubunda en yüksek kişi başı GSYIH'ya sahip ülke 2013'de Rusya $(16007,09 \$)$ iken, en düşük kişi baş1 GSYİH ise 2013'de $(3113,48 \$)$ Endonezya'ya aittir

Tablo 2. E7 Ülkelerinde 2010-2017 Yullar Arasında Kişi Başına GSYIH(USD)

\begin{tabular}{lcccccccc}
\hline Ülkeler & $\mathbf{2 0 1 0}$ & $\mathbf{2 0 1 1}$ & $\mathbf{2 0 1 2}$ & $\mathbf{2 0 1 3}$ & $\mathbf{2 0 1 4}$ & $\mathbf{2 0 1 5}$ & $\mathbf{2 0 1 6}$ & $\mathbf{2 0 1 7}$ \\
\hline Çin & 4650,51 & 5633,80 & 6337,88 & 7077,77 & 7683,50 & 8069,21 & 8117,27 & 8826,99 \\
Hindistan & 1345,77 & 1461,67 & 1446,99 & 1452,20 & 1576,00 & 1606,04 & 1717,47 & 1939,61 \\
Brezilya & 11224,15 & 13167,47 & 12291,47 & 12216,90 & 12026,62 & 8750,22 & 8639,37 & 9821,41 \\
Meksika & 9016,49 & 9912,58 & 9940,57 & 10400,56 & 10580,97 & 9290,76 & 8843,69 & 8902,63 \\
Endonezya & 3113,48 & 3634,28 & 3687,95 & 3620,66 & 3941,60 & 3334,55 & 3570,28 & 3846,86 \\
Rusya & 10674,99 & 14351,21 & 15434,57 & 16007,09 & 14125,91 & 9346,62 & 8759,04 & 10743,10 \\
Türkiye & 10672,40 & 11340,82 & 11720,31 & 12542,72 & 12127,46 & 10984,81 & 10862,73 & 10540,62 \\
\hline E7 Ortalamas1 & $\mathbf{7 2 4 2 , 5 4}$ & $\mathbf{8 5 0 0 , 2 6}$ & $\mathbf{8 6 9 4 , 2 5}$ & $\mathbf{9 0 4 5 , 4 1}$ & $\mathbf{8 8 6 6 , 0 1}$ & $\mathbf{7 3 4 0 , 3 2}$ & $\mathbf{7 2 1 5 , 6 9}$ & $\mathbf{7 8 0 3 , 0 3}$ \\
\hline
\end{tabular}

Kaynak: Dünya Bankası, Kişi Başına GSYİH (Cari, USD)

2010-2017 y1lları arasında E7 ülkelerinin kişi başına ortalama GSYİH 7200\$ üstündedir. E7 ülke grubunun 2010-2017 yılları arasındaki en düşük kişi başına ortalama GSYIH 2010'da 7242,54\$ olduğu ve en yüksek kişi başı ortalama GSYİH ise 2013'de 9045,41\$ olduğu görülmektedir.

\section{Literatür Taraması}

Yerli ve yabancı literatürde Girdi-Çıktı analizi ile kilit sektörlerin belirlenmesine yönelik birçok çalışma yapılmıştır. Çalışma, Türkiye'nin de dahil olduğu gelişme hızı yüksek olan ülke grubu E7'yi konu almas1, güncelliği ve E7 ülke ekonomilerine ait kilit sektörlerin tespit edilmesi bakımından literatürde yer alan diğer çalışmalardan farklılaşmaktadır.

Göktolga ve Akgül (2011) 19998 ve 2002 verileri ile Türkiye için kilit sektörleri tespit etmek için Girdi - Çıktı modeli ile yaptıkları analiz sonucunda 2002 yılına gelindiğinde ekonomik daralma yaşandığı ve dolayısıyla kilit sektörlerin 1998 ve 2002 ylllarında birbirinden farklı olduğunu bulmuştur. Her iki dönem içinde yalnızca giyim eşyalarının imalatı kilit sektörler arasında yer almıştır.

Yıldız ve Akduğan (2014) çalışmasında gelişmiş ve gelişmekte olan ülke ekonomilerini ele almıştır. Analizde, gelişmiş ülkeler için G7 ülkeleri ve gelişmekte olan ülkeler için ise Polonya, Çin, Arjantin, Brezilya, Hindistan, Endonezya, Yunanistan ve Türkiye ele alınmıştır. Analiz sonucunda, tüm ülkelerde istihdam çarpanının yüksek olduğu sektörün hizmet sektörü olduğu gözlenirken, katma değer çarpanı yüksek olan sektörün ise gelişmekte olan ülkeler için imalat sanayisi olduğu tespit edilmiştir.

Şenesen (2005) Türkiye ekonomisi için 1998 yılı Girdi-Çıktı verileri ile gerçekleştirdiği çalışmada gıda ve dokuma endüstrilerinde geriye bağlantı etkileri bakımından, petrol ürünleri ve ara girdi sağlayan endüstrilerin ise ileriye bağlantı etkileri açısından önemli endüstriler olduğunu bulmuştur. Ayrıca analiz sonucunda elde edilen bulguların benzer nitelikte çıkmaması dolayısıyla kilit sektör tanımlaması yapılmıştır.

Kula (2008) Türkiye ekonomisi için 2002 yılı Arz-Kullanım ve Girdi-Çıktı akım tabloları ile kilit sektörleri analiz etmiştir. Araştırma sonuçlarına göre kimyasal madde ve ürünlerin imalatı, gıda ve içecek imalatı, tekstil imalatı ile tarım ve ilgili hizmet faaliyetlerinin kilit sektörler olduğu tespit edilmiştir. 
Yılancı (2008) 1998 yllı Türkiye Girdi-Çıktı verileri üzerinden gerçekleştirdiği çalısmasında, Ticaret, Tarım, Kişisel Hizmetler ile Ulaşım ve haberleşme sektörlerinin kilit sektörler olduğunu ve bu sektörlere yapılacak yatırımlar ile büyüme hızının arttırlacağını tespit etmiştir.

Han vd. (2011) çalşsmalarında 2002 yllı için Türkiye imalat sanayisini Girdi-Çıktı analizi ile incelemişlerdir. Chenery-Watanabe ve Rasmussen yöntemlerine göre yapılan analizler sonucunda ana metal sanayi, yeniden değerlendirme, gida ve içecek ile tekstil ürünleri imalatı endüstrilerinin kilit sektörler oldukları belirlenmiştir.

Özdemir ve Yüksel (2006), 1985, 1990, 1996 ve 1998 yllı verilerini kullanarak Türkiye enerji sektörünü Girdi-Çıktı analizi ile inceledikleri çalışmalarında, imalat sanayi alt endüstrilerinde geri bağlantı hızının yüksek olduğunu ve eneriji sektörünün alt endüstrilerinin ileri ve geri bağlantı değerlerinin yüksek olduğunu tespit etmiştir.

Alp vd. (2017) çalışmalarında 2002 ve 2012 verileri ile Türkiye için kullanılarak endüstriler arası bağlantı etkileri ve kilit sektörleri analiz etmiştir. Analiz sonuçlarına göre, 2002 yllında kilit sektör olan kimyasal ürünlerinin imalatı, metal eşya sanayii ve yeniden değerlendirme endüstrileri 2012 yllına gelindiğinde kilit sektör olma özelliğini yitirmiştir. Bu sektörler yerine 2012 yllında ana metaller endüstrisinin kilit sektör niteliği kazandığı bulunmuştur.

Çondur vd. (2007) 1998 yll Türkiye verileri ile madencilik sektörü üzerine gerçekleştirdiği Girdi-Çıktı analizi sonucunda kilit sektörün, rafine edilmiș petrol ürünleri ve kok kömürü imalatı sektörü olduğunu belirlemiştir.

Ersungur vd. (2017) 1995, 2000, 2005, 2008 ve 2011 ylları WIOD verilerine göre gerçekleştirdikleri Girdi-Çıktı analizi sonucunda 2000'li yıllarda Türkiye'nin üretimde kullanılan ara mallarda dişa bağımlı bir hale gelmesine karşın Brezilya, Rusya, Çin ve Hindistan için yıllara göre farklı sektörlerde bu durumun kısmen ortaya çıktığı bulunmuştur. Ayrıca Türkiye'de yurtiçi taşımacilık ve tekstil ürünleri sektörlerinin, Brezilya'da madencilik sektörünün, Rusya'da nükleer yakıt ve rafine petrol, Çin'de kimyasal ürünlerin ve Hindistan'da ise temel metaller ve metal üretiminin kilit sektör oldukları tespit edilmiştir.

Ersungur ve Ekinci (2015) 1995, 2000, 2005, 2008 ve 2011 yllı WIOD verilerini kullanarak Türkiye, Güney Kore, Tayvan, Japonya ve Çin ekonomilerini Girdi-Çıktı modeline göre incelemişlerdir. Türkiye'nin ithal girdi bakımından dışa bağımlılığının yüksek düzeyde olduğunu bulmuştur. Analiz bulgularına göre, temel metaller ve üretimi, taş ocakçllğ̆ ve madencilik, kimyasallar ve kimyasal ürünler, nükleer yakıt ve rafine petrol, yurtiçi taşımacılık, makine ve diğer iș Faaliyetleri kiralanması, ulaștırma ekipmanları ve makine sektörleri ile elektrik ve optik ekipmanlar sektörlerinin söz konusu ülke grubu için kilit sektör oldukları belirlenmiştir.

Botric (2013) 2004 yllı verileri ile Hırvatistan ekonomisine yönelik gerçekleştirdiği Girdi-Çıktı analizinde farklı yöntemler ile ekonomideki kilit sektörleri tespit etmeye çalışıştır. Analiz sonucunda inşaat sektörü kilit sektör olarak bulunurken, hizmet sektörlerinin de sadece ihracat açısından değil ekonominin geneli için önemli bir sektör olduğu belirlenmiştir.

Jahangard ve Keshtvarz (2012) çalışmalarında İran için 1999, Güney Kore için 2005 ve Türkiye için 2002 ylı Girdi-Çıktı tablolarını kullanarak, söz konusu ülkeler için kilit sektörleri belirlemiştir. Analiz bulgularına göre üç ülkenin kilit sektörlerinin benzer olduğu bulunmuştur. Kilit sektörler; diğer imalatlar, Gıda ürünleri, meşrubat ve tütün imalatı, İnşaat, İletişim, Tekstil ve ilgili ürünlerin imalatı sektörleridir.

Tounsi vd. (2013) Fas ekonomisi için 1998 ve 2007 yıllarını Girdi-Çıktı analizi ile karşılaştırdıkları çalışmalarında, her iki yıl içinde gıda ve tütün endüstrisi sektörlerinin kilit sektör olduğunu bulmuştur.

Marconi vd. (2016) Brezilya ekonomisi Girdi-Çıktı analizi ile inceledikleri çalışmasında sektörler arasındaki ileri ve geri bağlantı seviyelerini ve ekonomideki kilit sektörleri belirlemeye çalışmıştır. Araştırma sonuçlarına göre, imalat ile ilgili sektörlerin Brezilya ekonomisinde kilit sektör oldukları belirlenmiştir.

\section{Uygulama}

Bu çalışmada E7 ülkeleri olan Çin, Hindistan, Brezilya, Meksika, Endonezya, Rusya ve Türkiye'nin 2014 yılı Girdi-Çıktı akım tabloları aracıllğılyla ekonomide faaliyet gösteren 56 sektörün toplam ileri ve toplam geri bağlantı yapıları ve ekonomideki kilit sektörleri talep yanlı Leontief modeline göre analiz edilmiştir. Analize dahil edilen veriler World Input Output Database (WIOD)'den alınmıştır. Verilerin 
WIOD'den temin edilmesinin nedeni hem en güncel verilerin olması hem de ülkelerin ekonomik yapılarının karşılaştırılabilmesi için ekonomide faaliyet gösteren endüstri sayılarının aynı olmasıdır

\section{Araştırma Yöntemi}

Bu çalışmada benimsenen metodoloji, Leontief (1951) tarafından geliştirilen girdi-çıktı modeline dayanmaktadır. Bir ekonominin toplam üretimi, ekonomide faaliyet gösteren farklı sektörler tarafindan ara tüketime yönelik olarak gerçekleştirilen üretimin toplamının ve nihai talebin sonucudur. Bu bağlamda ekonomik yapıyı belirleyebilmek ve daha etkin bir planlama gerçekleştirebilmek için ülkelerin endüstrilerarası ilişkileri doğru bir şekilde ortaya koyması gerekmektedir. Bu süreçte ise Girdi-Çıktı analizi önemli bir araç olarak karşımıza çıkmaktadır. Girdi-Çıktı analizi, ekonomiyi bir muhasebe sistemi gibi çift yönlü olarak incelemekte ve hem üretim hem de tüketim sürecini ele alarak, bir ekonominin ihtiyaç duyduğu birçok temel bilgiyi bizlere sunmaktadır.

Girdi-çıktı modelinin temel amacının, bir ekonomideki endüstrilerin birbirine bağımlılı̆ı̆ını analiz etmek olduğu söylenebilir. En temel haliyle bir Girdi-Çıktı modeli, bir endüstrinin ürününün ekonomi boyunca dağılımını ve etkilerini tanımlayan bir doğrusal denklem sisteminden oluşmaktadır. Girdi-çıtı modelleri hem ulusal hem de bölgesel düzeyde bir endüstrinin etkisi hakkında ayrıntılı bilgi sağlamada faydalı ve önemli bir araçtır. Ayrıca, çeşitli çarpanları hesaplayarak, bir sektörün istihdam, hane halkı geliri ve ekonomideki tüm endüstrilerin faaliyet seviyelerine olan etkisi ölçülebilir. Bu ölçümünde ekonomik kalkınma tahminleri açısından oldukça önemli olduğu göz önünde bulundurulmalıdır.

Girdi-Çıktı modelinin sağladığı önemli avantajlardan birisi de ekonomideki hem makro hem de mikro düzeydeki etkilerin değerlendirilmesine olanak sağlaması ve böylelikle ekonomide ortaya çıkan doğrudan ve dolaylı etkileri saptayabilmesi yeteneğidir (Ersungur vd., 2017, s.258). Ekonomideki doğrudan ve dolaylı etkilerin belirlenebilmesi sürecinde sektörler ve endüstriler arasındaki ileri ve geri yönlü etkilerin tespit edilebilmesi önemlidir.

Bir Girdi-Çıktı modeli çerçevesinde, belirli bir sektör tarafından yapılan üretim, ekonomideki diğer sektörler üzerinde iki tür ekonomik etkiye sahiptir. Eğer j sektörü üretimini arttırırsa, bu j'yi üretimde girdi olarak kullanan sektörlerde $\mathrm{j}$ sektöründen artan taleplerin olacağ1 anlamına gelir. Bu durum talep yanlı modelin nedensellik yönüdür ve geriye doğru bağlantı terimi, belirli bir sektörün girdi satın aldığ1 sektörlerden bu tür bir bağlantıyı ifade etmek için kullanılır. Diğer yandan, $j$ sektöründeki artan üretim aynı zamanda, diğer sektörlere kendi üretimleri için girdi olarak kullanılabilecek ilave $\mathrm{j}$ ürününün mevcut olduğu anlamına gelir. Yani, üretimlerinde $\mathrm{j}$ malını kullanan sektörler için, $\mathrm{j}$ sektöründen sağlanabilecek tedarikler artacaktır. Bu durum ise arz yanlı modelin nedensellik yönüdür. İleriye doğru bağlantı terimi, belirli bir sektörün çıktısını sattığı sektörlerle bu tür bir ara bağlantıyı belirtmek için kullanılır (Miller ve Blair, 2009, s.555). Kısaca geriye doğru bağlantılar, bir sektörün girdi sağlayan sektörlerle olan ilişkilerini ifade ederken, ileriye dönük bağlantılar ise bir sektördeki faaliyet ile o sektörün satışları arasındaki ilişkidir şeklinde tanımlanabilir (Matallah, 2007, s.290).

Kilit sektörler, bir ekonomide yüksek ileri ve geri yönlü etkiye sahip olan sektörlerdir. Kilit sektörlerin ekonominin geri kalanıyla ileri ve geri yönlü bağlantıları yüksek olduğu için, bu sektörlere yapılan yatırımların ekonomik büyümeyi en üst düzeye çıkarması beklenmektedir. Bu durum, kısıtlı kaynaklara sahip gelişmekte olan ülkeler için önem arz etmektedir. Ayrıca, kilit sektörler hem ulusal hem de bölgesel düzeyde uzun vadeli yapısal değişimi ve ekonomik kalkınmaya yönelik strateji politikalarını analiz etmek için de oldukça gerekli ve faydalıdır (Choi vd., 2014, s. 2).

Girdi-Çıktı modeline yönelik literatür incelendiğinde geri ve ileri yönlü bağlantıların hesaplanmasında iki farklı metodun olduğu görülmektedir. Bu metotlar, Chenery ve Watanabe (1958) tarafından geliştirilen girdi katsayıları matrisinin kullanıldığı yaklaşım ile Rasmussen’in (1957) öne çıkardığı ve sonrasında Hirschman'ın (1958) geliştirdiği Leontief ters matrisinin kullanıldığ yöntemdir. Chenery ve Watanabe'nin geliştirdiği yaklaşım doğrudan bağlantılar şeklinde adlandırılırken Rasmussen ve Hirschman'ın yöntemleri ise toplam bağlantılar olarak ifade edilmektedir (Gül ve Çakaloğlu, 2017, s. 140).

Girdi-Çıktı analizini diğer analizlerden ayıran önemli varsayımlardan biri, üretim sürecinde kullanılan girdi seviyesinin üretim seviyesinin doğrusal fonksiyonu olmasıdır. Sözü edilen bu doğrusal üretim fonksiyonu matematiksel olarak aşağıdaki gibi gösterilebilir (Aydoğuş, 2010, s. 45-46): 


$$
\begin{aligned}
& \mathrm{X}_{\mathrm{ij}}=\mathrm{X}_{\mathrm{ij} 0}+\mathrm{a}_{\mathrm{ij}} \mathrm{X}_{\mathrm{j}} \quad \quad(\mathrm{i}, \mathrm{j}=1,2, \ldots, \mathrm{N} \text { için }) \\
& \mathrm{X}_{\mathrm{ij}}=\mathrm{a}_{\mathrm{ij}} \mathrm{X}_{\mathrm{j}} \\
& \mathrm{a}_{\mathrm{ij}}=\mathrm{X}_{\mathrm{ij}} / \mathrm{X}_{\mathrm{j}}
\end{aligned}
$$

Denklemde yer alan "aij” katsayısı girdi katsayıdır ve bir birim j malının üretilebilmesi için ihtiyaç duyulan i malı miktarını göstermektedir. Bir ekonomideki tüm sektörlere ait olan girdi katsayılarından oluşan matrise "girdi katsayıları matrisi" denir ve A ile gösterilmektedir. Denklemdeki Xij ifadesi ise ekonomideki $\mathrm{j}$ sektörün üretim sürecinde i sektöründen aldığı ara girdi düzeyini ifade etmektedir.

Girdi-Çıktı yönteminin üretim denkleminin çözümü matematiksel olarak şu şekilde gösterilebilir (Özyurt, 2007, s. 123-124):

$$
\begin{aligned}
& X=A X+Y \\
& X-A X=Y \\
& (I-A) X=Y \\
& X=(I-A)^{-1} \cdot Y
\end{aligned}
$$

Denklemde yer alan X üretim vektörünü, Y nihai talep vektörünü “(I-A)-1” ise Leontief ters matrisini

\begin{tabular}{|c|c|c|c|c|c|c|c|c|c|c|c|c|c|}
\hline \multicolumn{2}{|c|}{ Türkiye } & \multicolumn{2}{|c|}{ Çin } & \multicolumn{2}{|c|}{ Hindistan } & \multicolumn{2}{|c|}{ Brezilya } & \multicolumn{2}{|c|}{ Meksika } & \multicolumn{2}{|c|}{ Endonezya } & \multicolumn{2}{|c|}{ Rusya } \\
\hline $\begin{array}{l}\text { Sek. } \\
\text { No. }\end{array}$ & $\begin{array}{l}\text { Top. } \\
\text { Geri } \\
\text { Bağ. }\end{array}$ & $\begin{array}{l}\text { Sek. } \\
\text { No. }\end{array}$ & $\begin{array}{l}\text { Top. } \\
\text { Geri } \\
\text { Bağ. }\end{array}$ & $\begin{array}{l}\text { Sek. } \\
\text { No. }\end{array}$ & $\begin{array}{l}\text { Top. } \\
\text { Geri } \\
\text { Bağ. }\end{array}$ & $\begin{array}{l}\text { Sek. } \\
\text { No. }\end{array}$ & $\begin{array}{l}\text { Top. } \\
\text { Geri } \\
\text { Bağ. }\end{array}$ & $\begin{array}{l}\text { Sek. } \\
\text { No. }\end{array}$ & $\begin{array}{l}\text { Top. } \\
\text { Geri } \\
\text { Bağ. }\end{array}$ & $\begin{array}{l}\text { Sek. } \\
\text { No. }\end{array}$ & $\begin{array}{l}\text { Top. } \\
\text { Geri } \\
\text { Bağ. }\end{array}$ & $\begin{array}{l}\text { Sek. } \\
\text { No. }\end{array}$ & $\begin{array}{l}\text { Top. } \\
\text { Geri } \\
\text { Bağ. }\end{array}$ \\
\hline 17 & 2,801 & 17 & 4,018 & 13 & 2,854 & 10 & 3,146 & 17 & 3,266 & 19 & 2,806 & 20 & 3,017 \\
\hline 15 & 2,749 & 18 & 3,986 & 20 & 2,813 & 11 & 2,662 & 33 & 2,861 & 24 & 2,772 & 33 & 2,628 \\
\hline 6 & 2,736 & 20 & 3,924 & 17 & 2,702 & 20 & 2,531 & 18 & 2,678 & 17 & 2,673 & 13 & 2,605 \\
\hline 22 & 2,729 & 21 & 3,824 & 11 & 2,699 & 33 & 2,501 & 20 & 2,628 & 18 & 2,539 & 19 & 2,505 \\
\hline 20 & 2,728 & 13 & 3,811 & 12 & 2,650 & 5 & 2,467 & 10 & 2,592 & 9 & 2,409 & 22 & 2,500 \\
\hline 24 & 2,668 & 11 & 3,805 & 9 & 2,636 & 13 & 2,463 & 56 & 2,579 & 8 & 2,350 & 5 & 2,478 \\
\hline 8 & 2,599 & 16 & 3,784 & 18 & 2,622 & 17 & 2,458 & 13 & 2,541 & 13 & 2,320 & 15 & 2,470 \\
\hline 13 & 2,595 & 15 & 3,727 & 22 & 2,609 & 18 & 2,431 & 16 & 2,451 & 12 & 2,266 & 17 & 2,463 \\
\hline 16 & 2,587 & 19 & 3,717 & 16 & 2,603 & 15 & 2,415 & 22 & 2,445 & 27 & 2,246 & 11 & 2,400 \\
\hline 10 & 2,583 & 27 & 3,530 & 19 & 2,582 & 8 & 2,348 & 11 & 2,442 & 16 & 2,222 & 24 & 2,400 \\
\hline
\end{tabular}
ifade etmektedir. Leontief ters matrisi, Girdi-Çıktı analizinin çözümünde büyük bir öneme sahiptir. Bir ekonomideki sektörlere ait olan toplam bağlantı etkileri Leontief ters matrisi aracilığılla hesaplanmaktadır. Leontief ters matrisinin satırında yer alan değerler toplam ileri bağlantı etkisini, sütununda yer alan değerler ise toplam geri bağlantı etkisini göstermektedir. Toplam ileri ve geri bağlantı etkilerinin formülleri şu şekilde gösterilebilir (Aydoğuş, 2010, s. 127-128):

Tablo 3. 2014 Yul E7 Ülkelerinde Toplam Geriye Bağlantı Etkileri (Illk On Sektör)

Kaynak: WIOD, National Input-Output Tables 2014'den faydalanarak yazarlar tarafindan hesaplanmıştır.

Diğer E7 ülkelerinde toplam geri bağlantı etkisinin yüksek olduğu sektörler ise sırasıyla Brezilya'da kok kömürü, rafine edilmiş petrol ürünlerinin imalatı, kimyasalların ve kimyasal ürünlerin imalatı, motorlu taşıt, römork ile yarı römork imalatı endüstrileri Meksika'da bilgisayar, elektronik ve optik ürünlerin imalatı, hava taşımacıllğı, elektrikli teçhizat imalatı iken Endonezya'da ise makine ve teçhizat imalatı, elektrik, gaz, buhar ve iklimlendirme ile bilgisayar, elektronik ve optik ürünlerin imalatı endüstrileridir.

Bir sektöre ait Leontief ters matrisinin satırında yer alan değerlerin toplamı o sektörün toplam ileri yönlü bağlant1 etkisini göstermektedir. E7 ülkelerindeki sektörlere ait toplam ileri bağlantı etkilerine ait değerler aşağıda yer alan Tablo 4'de gösterilmektedir. Türkiye'de toplam ileri bağlantı değeri yüksek olan ilk 3 sektör karayolu taşımacılı̆̆ı ve boru hatları üzerinden yapılan taşımacıllı, kimyasalların ve kimyasal ürünlerin imalatı ve temel metallerin imalatı iken Çin'de madencilik ve taş ocakçllğı, kimyasalların ve kimyasal ürünlerin imalatı ve temel metallerin imalatıdır.

Hindistan'da Leontief ters matrisinin sütun değerleri yüksek olan sektörler kimyasalların ve kimyasal ürünlerin imalatı, madencilik ve taş ocakçıllğı, temel metallerin imalatı; Brezilya'da kok kömürü, rafine edilmiş petrol ürünlerinin imalatı, madencilik, taş ocakçllğı, kimyasalların ve kimyasal ürünlerin imalatı 
iken Meksika'da ise idari ve destek hizmeti faaliyetleri, kimyasalların ve kimyasal ürünlerin imalatı ile madencilik ve taş ocakçılığ1 sektörleridir.

Tablo 4. 2014 Yılı E7 Ülkelerinde Toplam İleri Bağlantı Etkileri (Illk On Sektör)

\begin{tabular}{|c|c|c|c|c|c|c|c|c|c|c|c|c|c|}
\hline \multicolumn{2}{|c|}{ Türkiye } & \multicolumn{2}{|c|}{ Çin } & \multicolumn{2}{|c|}{ Hindistan } & \multicolumn{2}{|c|}{ Brezilya } & \multicolumn{2}{|c|}{ Meksika } & \multicolumn{2}{|c|}{ Endonezya } & \multicolumn{2}{|c|}{ Rusya } \\
\hline $\begin{array}{l}\text { Sek. } \\
\text { No. }\end{array}$ & $\begin{array}{l}\text { Top. } \\
\text { İleri } \\
\text { Bağ. }\end{array}$ & $\begin{array}{l}\text { Sek. } \\
\text { No. }\end{array}$ & $\begin{array}{l}\text { Top. } \\
\text { İleri } \\
\text { Bağ. }\end{array}$ & $\begin{array}{l}\text { Sek. } \\
\text { No. }\end{array}$ & $\begin{array}{l}\text { Top. } \\
\text { İleri } \\
\text { Bağ. }\end{array}$ & $\begin{array}{l}\text { Sek. } \\
\text { No. }\end{array}$ & $\begin{array}{l}\text { Top. } \\
\text { İleri } \\
\text { Bağ. }\end{array}$ & $\begin{array}{l}\text { Sek. } \\
\text { No. }\end{array}$ & $\begin{array}{l}\text { Top. } \\
\text { İleri } \\
\text { Bağ. }\end{array}$ & $\begin{array}{l}\text { Sek. } \\
\text { No. }\end{array}$ & $\begin{array}{l}\text { Top. } \\
\text { İleri } \\
\text { Bağ. }\end{array}$ & $\begin{array}{l}\text { Sek. } \\
\text { No. }\end{array}$ & $\begin{array}{l}\text { Top. } \\
\text { İleri } \\
\text { Bağ. }\end{array}$ \\
\hline 31 & 5,107 & 4 & 9,117 & 11 & 4,868 & 10 & 4,255 & 50 & 5,907 & 4 & 6,153 & 29 & 4,679 \\
\hline 11 & 4,777 & 11 & 8,051 & 4 & 4,602 & 4 & 3,915 & 11 & 5,717 & 29 & 4,377 & 24 & 4,363 \\
\hline 15 & 4,429 & 15 & 6,837 & 15 & 4,502 & 11 & 3,886 & 4 & 5,089 & 10 & 4,084 & 10 & 4,290 \\
\hline 24 & 4,110 & 24 & 6,048 & 31 & 3,941 & 30 & 3,712 & 10 & 4,872 & 11 & 3,942 & 15 & 3,945 \\
\hline 29 & 3,872 & 17 & 5,870 & 30 & 3,476 & 50 & 3,705 & 29 & 3,313 & 24 & 3,208 & 50 & 3,568 \\
\hline 49 & 3,537 & 10 & 5,629 & 24 & 2,655 & 41 & 3,425 & 15 & 3,290 & 19 & 3,074 & 20 & 3,069 \\
\hline 4 & 3,116 & 5 & 5,408 & 41 & 2,654 & 31 & 3,052 & 17 & 3,082 & 30 & 2,946 & 30 & 3,011 \\
\hline 10 & 3,081 & 29 & 4,980 & 29 & 2,651 & 29 & 2,927 & 30 & 2,974 & 8 & 2,599 & 4 & 2,764 \\
\hline 41 & 2,930 & 1 & 4,898 & 10 & 2,534 & 45 & 2,882 & 8 & 2,473 & 1 & 2,540 & 11 & 2,639 \\
\hline 30 & 2,929 & 41 & 4,303 & 22 & 2,317 & 24 & 2,521 & 20 & 2,396 & 41 & 2,469 & 51 & 2,311 \\
\hline
\end{tabular}

Kaynak: WIOD, National Input-Output Tables 2014'den faydalanarak yazarlar tarafindan hesaplanmıştır.

E7 ülkelerinden Rusya'da toplam ileri bağlantısı yüksek değer alan sektörler sırası ile motorlu taşıtlar ve motosikletler hariç toptan satıs, elektrik, gaz, buhar, iklimlendirme, kok kömürü ve rafine edilmiş petrol ürünlerinin imalatı sektörleriyken Endonezya'daki sektörler ise madencilik, taş ocakçılığı, motorlu taşıtlar, motosikletler hariç toptan satışı, kok kömürü ve rafine edilmiş petrol ürünlerinin imalatı sektörleridir.

\section{Sonuç ve Değerlendirme}

İktisadi kalkınma ve büyümenin sağlanması tüm ülkeler için büyük önem arz etse de bu durum özellikle gelişmekte olan ülke ekonomileri açısından öncelikli ekonomi politikalarının başında gelmektedir. Kit kaynaklar ve yetersiz sermaye yapıları dolayısıyla bu ülkeler tüm sektörlerinde eş anlı bir ilerleme sağlayamamaktadır. Dolayısıyla dengeli büyüme modelinin hayata geçirilmesi gelişmekte olan ülkeler açısından pek gerçekçi bir hedef değildir. Bu bakımdan, rekabet gücüne sahip ve ilerleme potansiyeline sahip sektörlerin seçilmesi ve bu sektörlere yapılacak yatırımlar ile ekonominin genelinde bir canlanma sağlanması bu ülkeler için daha gerçekçi bir büyüme modeli olarak karşımıza çıkmaktadır. Bu süreçte kıt kaynaklara sahip gelişmekte olan ülkelerin bu kaynaklarını daha etkin ve verimli kullanabilmesi sürecinde endüstriler arası analizin önemi artmaktadır.

Özellikle 2000'li yıllarda yüksek gelişme hızına sahip olan ülkeler dünyanın dikkatini üstüne çekmeye başlamıştır. Bu ülkeler ise öncelikle BRICS ülkeleri olan Çin, Brezilya, Hindistan ve Rusya iken daha sonra bu ülkelerin arasında Meksika, Endonezya ve Türkiye katılmıştır. Yüksek gelişme hızına sahip bu 7 ülke önce BRICS+3 olarak adlandırllirken 2006 yllında ünlü ekonomistler John Crofton Hawksworth ve Gordon Cookson tarafindan E7(Emerging7) ülkeleri olarak literatürde yer almaya başlamıştır. E7 yani gelişmekte olan ülkeler arasındaki yükselen yedi ülke özellikle ekonomik büyüme hızları nispeten daha yüksek olduğundan diğer ülke gruplarından ayrılmaktadır.

E7 ülkeleri genellikle belirli sektörlerindeki gelişmiş yapısı sebebiyle yüksek büyüme hızını sağlamaktadır. Bu bağlamda, E7 ülkelerinin endüstri yapısının analiz edilmesi, endüstriler arasındaki ilişkilerin belirlenmesi ve yüksek büyüme hızını sağlayan kilit sektörlerin tespit edilmesi bu çalışmanın amaçlarıdır. Bu amaç doğrultusunda, çalışmada E7 ülkelerinin ekonomileri Girdi-Çıktı modeliyle analiz edilerek bu ülkelerin toplam bağlantı değerleri ve kilit sektörleri belirlenmiştir. Bir sektörün ekonomi için kilit ya da lokomotif sektör olarak adlandırılabilmesi için o sektörün toplam ileri ve toplam geri yönlü bağlantı etkilerinin yüksek olması gerekmektedir.

Literatürde E7 ülkelerinin ekonomik analizini girdi-çıtı modeli ile incelenmesini konu alan başka bir çalışma olmadığından, bu çalışmadan elde edilen sonuçların karşılaştırılması mümkün değildir. Fakat aynı ülkeleri konu alan çalışmalar açısından bir karşılaştırma yapilması mümkündür. Yıldız ve Akduğan 2014 yılında gerçekleştirdikleri çalışmada, OECD’ye ait 2006 yılı Girdi-Çıktı tabloları aracıllğıyla G7 ülkeleri ile gelişmekte olan ülke ekonomileri karşılaştırılmıştır. Analiz sonucunda, gelişmekte olan ülkelerde (Türkiye, Hindistan, Endonezya, Çin, Yunanistan, Macaristan, Polonya, Arjantin ve Brezilya) kilit sektörün imalat sanayi olduğu tespit edilmiştir. Alp ve diğerlerinin 2017 yllında yaptığı çalışmada ise TÜİK'e ait 2002 ve 2012 verileri ile Türkiye ekonomisi için kilit sektörler analiz edilmiştir. Analiz sonucuna göre 2002 yllında kimyasal ürünlerinin imalatı, metal eşya sanayii ve yeniden değerlendirme endüstrilerinin 2012 yllında ise 
ana metaller endüstrisinin kilit sektör olduğu belirlenmiştir. Yapılan bu çalışmaya tarih ve ülke bakımından en yakın çalışması ise Ersungur vd. (2017) tarafından yapılmıştır. Çalışmada 1995, 2000, 2005, 2008 ve 2011 yıllarına ait WIOD verileri ile Türkiye, Rusya, Çin, Brezilya ve Hindistan ekonomileri girdi-çıktı modeli ile incelenmiștir. Analiz sonucunda Türkiye'de yurtiçi taşımacllık ve tekstil ürünleri, Brezilya'da madencilik, Rusya'da nükleer yakıt ve rafine petrol, Çin'de kimyasal ürünlerin ve Hindistan'da ise temel metaller ve metal üretiminin kilit sektör oldukları bulunmuştur.

Girdi-Çıktı modeli ile E7 ülkelerinin ekonomileri incelendiği bu çalısmada 2014 yllında Türkiye'de kilit sektörler temel metallerin imalatı, elektrik, gaz, buhar ve iklimlendirme ile tekstil, giyim eşyası ve deri ürünleri imalatı, Çin'de Bilgisayar, elektronik ve optik ürünlerin imalatı, kimyasalların ve kimyasal ürünlerin imalatı ve temel metallerin imalatıken Rusya'nın kilit sektörleri ise kimyasalların ve kimyasal ürünlerin imalatı, elektrik, gaz, buhar ve iklimlendirme ile kok kömürü ve rafine edilmiş petrol ürünlerinin imalatı olarak karşımıza çıkmaktadır. 2014 yllında Hindistan ekonomisindeki kilit sektörler kimyasalların ve kimyasal ürünlerin imalatı, mobilya imalatt; diğer imalatlar, Brezilya'da kok kömürü ve rafine edilmiş petrol ürünlerinin imalatı ile kimyasalların ve kimyasal ürünlerin imalatı sektörleridir. Meksika'da motorlu taşıt, römork ve yarı römork imalatı ile kok kömürü ve rafine edilmiş petrol ürünlerinin imalatı sektörleri kilit özellikteyken Endonezya'da ise makine ve teçhizat imalatı, elektrik, gaz, buhar ve iklimlendirme ile kağıt ve kağıt ürünlerinin imalatı sektörleri ülke için kilit sektör özelliğine sahiptir.

Kilit sektörler ülkelerin gelişme hızını artırması için potansiyel sahibi ve güçlü sektörleri bize göstermektedir. Aynı zamanda kilit sektörler, ülkelerin ihracatında da önemli pay edinme potansiyeline sahiptirler. Dolayısıyla kaynakların kıt olduğu gelişmekte olan ülkeler için bu sektörlerde yaşanacak gelişmeler ekonominin genelinde bir canlanmaya ve ekonomik büyümeye kap1 aralayacaktır. Bu bakımdan, E7 ülkelerinin kilit sektörlere yönlendirecekleri ya da yapacakları yeni yatırımlar sonucunda gelişme hızlarını arttıracakları ve yaşanacak bu gelişme ile ekonominin genelinde de bir canlanma ve ilerleme sağlanacağı söylenebilir. Dolayısıyla E7 ülkeleri bu kilit sektörlere yapacakları yatırımlar ile ekonomik gelişme hızını daha da arttırabilecek ve bu süreçte ise kilit sektörler ekonomik gelişme açısından lokomotif bir rol oynayacaktır. Ekonomik karar vericilerin yapılacak kalkınma planlarında kilit sektörlere öncelik vermesi ile ulusal kalkınma ve büyüme sürecinde ülkeler önemli bir ilerleme sağlayabilirler. Bu bağlamda, analiz sonucunda elde edilen bulgulara göre E7 ülkeleri için kilit sektörlere yapılacak yatırımlara öncelik vermesi ve yatırımların bu sektörlere kanalize edilmesi önerisinde bulunulabilir.

\section{Kaynakça}

Alp, E., Kök, R. ve Ozan, B. M. (2017). Türkiye ekonomisinde sürükleyici endüstri analizi: 2002-2012 karş1laştırması. Kafkas Üniversitesi İktisadi ve İdari Bilimler Fakültesi Dergisi, 8(16), 211-241.

Aydoğuş, O. (2010). Girdi-çıktı modellerine giriş. Ankara: Efil Yayınevi.

Botric, V. (2013). Indetifying key sectors in Crotian economy based on input-output tables. The Institute of Economics, Zagreb, EIZ Working Papers. No.1302, 5-26.

Chenery, H. B. ve Watanabe, T. (1958). International comparisons of the structure of production. Econometrica, 26(4), 487-521.

Choi, S., Ji, H. ve Zhao, X. (2014). Identifying key sectors using regional input-output model at sub-national level, 54th Congress of the European Regional Science Association Regional Development Globalisation Best Practices, 26-29 August 2014, Russia: St. Petersburg.

Çondur, F. ve Evlimoğlu, E. (2007). Türkiye'de madencilik sektörünün girdi-çıktı analizi yöntemiyle incelenmesi. Sosyal Bilimler Dergisi, 17, 25-41.

Ersungur, Ş. M. ve Ekinci, E. D. (2015). Türkiye ve Doğu Asya ülkeleri arasındaki dış ticaret ilişkileri: Girdi-çıtıtı yöntemi ile bir analiz. Atatürk Üniversitesi İktisadi ve İdari Bilimler Fakültesi, 29(4), 721-748.

Ersungur, Ş. M., Bayramoğlu, T. ve Pabuçcu, H. (2017). Türkiye’nin Almanya, Rusya ve Çin ile ticari ilişkileri: girdiçıtı analizi ile bir uygulama. Gaziantep University Journal of Social Science, 16(1), 252-267.

Ersungur, Ş. M., Boz, Ç. F. ve Çınar, Ö. (2017). Türkiye ile BRICS ülkeleri arasındaki dış ticaret ilişkileri: Girdi-Çıktı yöntemiyle bir analiz. Business and Economics Research Journal, 8(3), 395-412.

Göktolga, Z. ve Akgül, Y. (2011). Türkiye ekonomisinin yapısal analizi: 1998 ve 2002 yılları girdi-çıtı analizi örneği. Akademik Yaklassım Dergisi, 2(2), 110-128.

Gül, Z. B. ve Çakaloğlu, M. (2017). İnşaat sektörünün dinamikleri: Türkiye için 2000-2014 girdi-ç1ktı analizi. Akdeniz Üniversitesi İktisadi ve İdari Bilimler Fakültesi Dergisi, 36, 130-155.

Han, E., Tosunoğlu, T. ve Özsoy, C. (2011). Türk imalat sanayinde geri ve ileri bağlantılar: G-Ç tablosuna dayalı yapisal bir çözümleme. TISK Akademi, 6(11), 104-129.

Hirschman, A. O. (1958). The strategy of economic development. New Haven: Yale University Press. 
Jahangard, E. ve Keshtvarz, V. (2012). Identification of key sectors for Iran, South Korea and Turkey economies: A network theory approach. Iranian Economic Review, 16(32), 41-63.

Kula, A. M. (2008). Supply-use and input-output tables, backward and forward linkages of the Turkish economy. 16th Inforum World Conference in Northern Cyprus, 01-05 September, Northern Cyprus.

Leontief, W. (1951). The structure of the American economy. New York: Oxford University Press.

Marconi, N., Rocha I. L. ve Magacho, G. R. (2016). Sectoral capabilities and productive structure: An input-output analysis of the key sectors of Brazilian economy. Brazilian Journal of Political Economy, 36(3), 470-492.

Matallah, K. E. (2007). A multiplier and linkage analysis: Case of Algeria. Journal of North Africa Economies, 1, 287-300.

Miller, R. E. ve Blair, P. D. (2009). Input-output analysis: foundations and extensions. Cambridge: Cambridge University Press.

Özdemir A. ve Yüksel, F. (2006). Türkiye'de enerji sektörünün ileri ve geri bağlantı etkileri. Yönetim ve Ekonomike Dergisi, 13(2), 1-18.

Özyurt, H. (2007). İktisadi planlama. Trabzon: Derya Kitabevi.

Rasmussen, P. N. (1957). Studies in inter-sectoral relations. Amsterdam: North-Holland.

Şenesen, G. G. (2005). Türkiye'nin üretim yapısı g-ç modeli temel bulgular. İstanbul: TÜSL̇AD büyüme stratejileri diz̨isi 3, Yayın no. TÜSİAD-T/2005-06/400.

Timmer, M. P., Dietzenbacher, E., Los, B. Stehrer, R. ve De Vries, G. J. (2015). An illustrated user guide to the world input-output databes: The case of global automotive production. Review of International Economics, 23, 575605.

Tounsi, S., Ezzahid, E. H., El Alaoui, A. ve Nihou, A. (2013). Key sectors in the Moroccan economy: An application of input-output analysis. Economics: The open-access, Open-Assessment EJournal, 7(18). http://dx.doi.org/10.5018/economics-ejournal.ja.2013-18.

World Input-Output Database (WIOD). National Input-Output Tables, http://www.wiod.org/database/niots16 (Erişim Tarihi 20.03.2019).

Worldbank, Gross Domestic Product (GDP) Growth Rates, (Annual,\%), https://data.worldbank.org/indicator/NY.GDP.MKTP.KD.ZG?locations (Erişim Tarihi:15.04.2019)

Worldbank, Gross Domestic Product (GDP) Per Capita, (Current,USD), https://data.worldbank.org/indicator/NY.GDP.PCAP.CD?locations (Erişim Tarihi:10.04.2019).

Yılancı, V. (2008). Türkiye ekonomisi için kilit sektörün belirlenmesi: G-Ç analizi yaklaşımı. İktisat Fakültesi Mecmuası, 58(2), 75-86.

Yıldız, N. ve Akduğan, U. (2014). Girdi-çıktı tabloları ile sektörler arası ilişkilerin analizi: Seçilmiş ülke örnekleri. Akademik Bakıș Dergisi, 44. 
Ek - WIOD Sektör Sinfflandirmalar ve Kodlarn

\begin{tabular}{|c|c|c|}
\hline $\begin{array}{c}\text { Sek. } \\
\text { No }\end{array}$ & $\begin{array}{c}\text { Sek. } \\
\text { Kodu }\end{array}$ & Sektör Adı \\
\hline 1 & A01 & Bitkisel ve hayvansal üretim, avc1lık ve ilgili hizmet faaliyetleri \\
\hline 2 & $\mathrm{~A} 02$ & Ormancilik \\
\hline 3 & $\mathrm{~A} 03$ & Balıkçılık ve su ürünleri yetiştiriciliği \\
\hline 4 & B & Madencilik ve tașocakçılığı \\
\hline 5 & $\mathrm{C} 10-\mathrm{C} 12$ & Gıda ürünleri, içecek ve tütün ürünleri imalatı \\
\hline 6 & $\mathrm{C} 13-\mathrm{C} 15$ & Tekstil, giyim eşyası ve deri ürünleri imalatı \\
\hline 7 & $\mathrm{C} 16$ & Mobilya hariç, odun ve odun ve mantar ürünleri imalatı; hasır ve örgü malzemelerinin imalatı \\
\hline 8 & $\mathrm{C} 17$ & Kağıt ve kağıt ürünlerinin imalatı \\
\hline 9 & $\mathrm{C} 18$ & Kayıtlı ortamların basılması ve çoğaltılması \\
\hline 10 & $\mathrm{C} 19$ & Kok kömürü ve rafine edilmiș petrol ürünlerinin imalatı \\
\hline 11 & $\mathrm{C} 20$ & Kimyasalların ve kimyasal ürünlerin imalatı \\
\hline 12 & $\mathrm{C} 21$ & Temel eczacılık ürünleri ve farmasötik preparatların imalatı \\
\hline 13 & $\mathrm{C} 22$ & Kauçuk ve plastik ürünlerin imalatı \\
\hline 14 & $\mathrm{C} 23$ & Diğer metalik olmayan mineral ürünlerin imalatı \\
\hline 15 & $\mathrm{C} 24$ & Bazik metal imalatı \\
\hline 16 & $\mathrm{C} 25$ & Makine ve teçhizat hariç, fabrikasyon metal ürünleri imalatı \\
\hline 17 & $\mathrm{C} 26$ & Bilgisayar, elektronik ve optik ürünlerin imalatı \\
\hline 18 & $\mathrm{C} 27$ & Elektrikli ekipman imalatı \\
\hline 19 & $\mathrm{C} 28$ & Makine ve teçhizat imalatı \\
\hline 20 & $\mathrm{C} 29$ & Motorlu kara tașıtlarmın, römorkların ve yarı römorkların imalatı \\
\hline 21 & $\mathrm{C} 30$ & Diğer ulașım araçlanının imalatı \\
\hline 22 & C31_C32 & Mobilya imalat1; diğer imalat \\
\hline 23 & $\mathrm{C} 33$ & Makine ve teçhizat tamiri ve montajı \\
\hline 24 & D35 & Elektrik, gaz, buhar ve iklimlendirme \\
\hline 25 & E36 & Su toplama, antma ve tedarik \\
\hline 26 & E37-E39 & Kanalizasyon; atık toplama, arıtma, geri kazanımı ve diğer atık yönetimi hizmetleri \\
\hline 27 & $\mathrm{~F}$ & İnșaat \\
\hline 28 & G45 & Motorlu kara tașitlarının ve motosikletlerin toptan ve perakende ticareti ve onarımı \\
\hline 29 & G46 & Motorlu kara taşıtları ve motosikletler hariç toptan satıș \\
\hline 30 & G47 & Motorlu tașitlar ve motosikletler hariç perakende ticaret \\
\hline 31 & $\mathrm{H} 49$ & Kara tașımacılığı ve boru hatlan ile tașımacılığı \\
\hline 32 & $\mathrm{H} 50$ & Su ulaștırma \\
\hline 33 & H51 & Hava Tașımacılığı \\
\hline 34 & H52 & Depolama ve nakliye için destekleyici faaliyetler \\
\hline 35 & H53 & Posta ve kurye faaliyetleri \\
\hline 36 & I & Konaklama ve yemek servisi faaliyetleri \\
\hline 37 & J58 & Yayıncılık faaliyetleri \\
\hline 38 & J59_J60 & Sinema filmi, video ve televizyon programı prodüksiyonu, ses kaydı ve müzik yayıncılığ 1 faaliyetleri \\
\hline 39 & J61 & Telekomünikasyon \\
\hline 40 & J62 J63 & Bilgisayar programlama, danıșmanlık ve ilgili faaliyetler; bilgi hizmeti faaliyetleri \\
\hline 41 & K64 & Sigorta ve emeklilik fonları hariç finansal hizmet faaliyetleri \\
\hline 42 & K65 & Zorunlu sosyal güvenlik hariç, sigorta, reasürans ve emeklilik fonları \\
\hline 43 & K66 & Finansal hizmetlere ve sigorta faaliyetlerine yardımcı faaliyetler \\
\hline 44 & L68 & Gayrimenkul faaliyetleri \\
\hline 45 & M69 M70 & Hukuk ve muhasebe faaliyetleri; merkez ofislerin faaliyetleri; yönetim danıșmanlığı faaliyetleri \\
\hline 46 & M71 & Mimari ve mühendislik faaliyetleri; teknik test ve analiz \\
\hline 47 & M72 & Bilimsel arașturma ve geliștirme \\
\hline 48 & M73 & Reklam ve pazar araștırması \\
\hline 49 & M74_M75 & Diğer mesleki, bilimsel ve teknik faaliyetler; veterinerlik faaliyetleri \\
\hline 50 & $\mathrm{~N}$ & İdari ve destek hizmeti faaliyetleri \\
\hline 51 & O84 & Kamu yönetimi ve savunma; zorunlu sosyal güvenlik \\
\hline 52 & P85 & Eğitim \\
\hline 53 & Q & İnsan sağlıği ve sosyal hizmet faaliyetleri \\
\hline 54 & R_S & Diğer servis faaliyetleri \\
\hline 55 & $\mathrm{~T}$ & İșveren olarak hanelerin faaliyetleri; Hane halkının kendi kullanımına yönelik faaliyetleri \\
\hline 56 & $\mathrm{U}$ & Uluslararası örgütler ve temsilciliklerinin faaliyetleri \\
\hline
\end{tabular}




\section{EXTENDED ABSTRACT}

Although economic development and growth are crucial for all countries, this is one of the primary economic policies especially for developing countries. Due to scarce resources and insufficient capital structures, these countries cannot achieve simultaneous progress in all sectors. Therefore, the implementation of a balanced growth model is not a realistic goal for developing countries. In this respect, the choice of sectors with competitive potential and the potential for progress and the revival of the economy with these investments are a more realistic growth model for these countries. In this process, the importance of inter-industry analysis is increasing in the process of developing more efficient and efficient resources of developing countries with scarce resources.

Especially in the 2000s, countries with high growth rate began to attract the attention of the world. These countries are BRICS countries such as China, Brazil, India and Russia. Then between these countries, Mexico, Indonesia and Turkey are added. These 7 countries with high growth rates were first called BRICS + 3, but in 2006, the famous economists John Crofton Hawksworth and Gordon Cookson began to take part in the literature as E7 (Emerging7) countries. The seven emerging countries among E7, ie developing countries, are distinguished from other country groups, especially as their economic growth rates are relatively high.

E7 countries generally provide a high growth rate due to their advanced structure in certain sectors. In this context, it is the objectives of this study to analyze the industrial structure of E7 countries, to determine the relations between industries and to identify key sectors that provide high growth rate. For this purpose, the economies of the E7 countries were analyzed by the Input-Output model.

The study is important in determining the key sectors of E7 countries, which are referred to as countries with high growth rates, and to direct investments towards the right sectors in the planning process. It can be said that the identification of key sectors will be an important resource for the development policies of economic decision makers and the more effective results of these policies. Analysis data is obtained from World Input-Output Database (WIOD). These data are the Input-Output tables of E7 countries in 2014. According to WIOD data, there are 56 sectors operating in the country's economies.

In domestic and foreign literature, many studies have been done to determine the key sectors with Input-Output analysis. The study differs from the other studies in the literature in terms of the fact that the group of countries with high growth rate is subject to E7, the currentness and the determination of the key sectors of E7 countries' economies. In order for a sector to be called the key or locomotive sector for the economy, the total forward and total backward link effects of the sector should be high. Backward links can be defined as the relationship of a sector with sectors that provide input, while forward links can be defined as the relationship between the activity in a sector and the sales of that sector. In this context, the economics of E7 countries were analyzed by Input-Output analysis. Leontief inverse matrix, total backward and total forward linkage effects were determined in the study.

Since there is no other study on the economic analysis of E7 countries with the input-output model in the literature, it is not possible to compare the results obtained from this study. However, it is possible to make a comparison in terms of studies in the same countries. In their study conducted in 2014, Yildiz and Akduğan compared the economies of developing countries with G7 countries through the 2006 Input-Output tables of the OECD. As a result of the analysis, it was determined that the key sector was the manufacturing industry in developing countries (Korea, India, Indonesia, China, Greece, Hungary, Poland, Argentina, and Brazil). In the study conducted by Alp et al. In 2017, the key sectors for the Turkish economy were analyzed with the 2002 and 2012 data of TURKSTAT. According to the results of the analysis, it was determined that the manufacturing of chemical products, metal goods industry and reevaluation industries were the key sectors in 2002, while the base metals industry was the key sector in 2012. The closest study of this study in terms of topicality and countries is Ersungur et al. (2017). In this study, the data of 1995, 2000, 2005, 2008 and 2011 and the economies of Turkey, Russia, China, Brazil, and India were analyzed with the input-output model. As a result, domestic transportation and textile products in Turkey, mining in Brazil, nuclear fuel and refined petroleum in Russia, chemical products in China and basic metals and metal production in India were found to be the key sectors.

Key sectors in the Turkey economy; Production of basic metals, electricity, gas, steam and air conditioning and textiles, apparel and leather products manufacturing sectors were determined. Key 
sectors in the Chinese economy; Manufacture of computer, electronic and optical products, Manufacture of chemicals and chemical products, Manufacture of basic metals. The key sectors of Russia are the manufacture of chemicals and chemical products, electricity, gas, steam and air conditioning, and the production of coke and refined petroleum products.

The key sectors in the Indian economy in 2014 are the manufacture of chemicals and chemical products, furniture manufacturing and other manufacturing sectors. The key sectors for the Brazilian economy are as follows; Manufacture of coke and refined petroleum products and manufacturing of chemicals and chemical products. In Mexico, the manufacture of motor vehicles, trailers and semi-trailers and the production of coke and refined petroleum products have been identified as sectors of key economy. For the Indonesian economy, the manufacturing of machinery and equipment, electricity, gas, steam and air conditioning and paper and paper products sectors are key for the country.

The key sectors show us the potential and powerful sectors to increase the pace of development of countries. At the same time, key sectors have the potential to gain significant share in the exports of countries. Therefore, the developments in these sectors for developing countries where resources are scarce will open the way for a revival and economic growth in the overall economy. In this respect, it can be said that the E7 countries will increase their growth rates as a result of the investments they will lead to the key sectors and a recovery and progress will be achieved in the overall economy. Therefore, E7 countries will be able to increase the speed of economic development with their investments in key sectors and in this process, key sectors will play a leading role in economic development. With economic decision-makers prioritizing key sectors in their development plans, countries can make significant progress in the national development and growth process. In this context, according to the findings of the analysis, it can be suggested that E7 countries should prioritize investments in key sectors and channel investments into key sectors. 